\title{
Comparison of Accessibility among Vision-impaired Patients Visiting Mobile and Stationary Hospitals in Rural Bangladesh
}

\author{
Md. Ferdaws Alam', Virasakdi Chongsuvivatwong², Hasib Mahmud', Pradip Sen Gupta' \\ 'Impact Foundation Bangladesh, 3rd Floor, Cosmopoliton Centre, House 22/2, Block B, Babor Road, Muhammadpur, \\ Dhaka I207, Bangladesh; ${ }^{2}$ Epidemiology Unit, Faculty of Medicine, Prince of Songkla University, Hat Yai, Songkla 90I I0, Thailand
}

\begin{abstract}
The aim of this study is to compare accessibility of vision-impaired (VI) patients to other eyecare centres before attending the mobile and stationary hospitals. Under a cross-sectional study design, VI patients were consecutively enrolled if they visited one of the three Impact Foundation Hospitals—one mobile and two stationary hospitals. The cost and service output of all hospitals were also reviewed; $27.7 \%$ of patients at the mobile and $36.8 \%$ at the two stationary hospitals had sought eyecare at other health facilities in the past. Mobile hospital patients lived closer to the hospital but spent more time in travelling, bore less direct cost, needed less extra support, and had a higher level of satisfaction on the service. They also identified more barriers to access eyecare in the past. The mobile hospital had a higher percentage of patients with accessibility problems and should continue to help the remote population in overcoming these problems.
\end{abstract}

Key words: Health science accessibility; Mobile hospital; Vision impairment; Bangladesh

\section{INTRODUCTION}

Worldwide, 285 million people are vision-impaired; about $90 \%$ of them live in developing countries (1) - around 62 million in the South Asia region (2) and 6.65 million in Bangladesh (3). About $80 \%$ of all vision impairment (VI) are avoidable (1). People with VI are a great burden on Bangladesh, with an annual incidence of 130,000 new cases (3).

In 2009, the population of Bangladesh was approximately 146 million (4). The majority (74\%) lives in rural areas, and $36 \%$ of the total population lives below the poverty-line (5). The Government provides rural health services through community clinics, union subcentres and subdistrict health complexes free of charge (6). Only 141 hospitals provide eyecare services; of them, 71, 56, and 14 are run by the Government, non-governmental organizations (NGOs), and private sectors respec-

Correspondence and reprint requests:

Md. Ferdaws Alam

Impact Foundation Bangladesh

3rd Floor, Cosmopoliton Centre

House 22/2, Block B, Babor Road

Muhammadpur, Dhaka 1207

Bangladesh

Email: ferdous_5068@yahoo.com

Fax: 880-2-9893266 tively. Eyecare services are virtually non-existent at the rural community and subdistrict level (7).

Impact Foundation Bangladesh (IFB) is a charitable, non-governmental organization which was initiated in 1993. Its mission is to prevent disability by improving the living conditions of disadvantaged people and communities. Impact 'Jibon Tari' (IJT) Floating Hospital was the first and unique project of its kind in Bangladesh, starting its journey in April 1999. The hospital floats along the riverside of the country and moves to a new site every 5-6 months. It provides specialized curative health services, with special emphasis on avoidable disabilities in rural areas. About $60 \%$ of outpatients have eye problems, and more than $80 \%$ of all operations performed there involve the eyes.

The Foundation also initiated Impact Masudul Haque Memorial Community Health Centre (IMCHC) in April 2002 in Chuadanga district. It provides multiple services, including eyecare to the poorer communities. Impact 'Jibon Mela' (IJM) is another comprehensive programme of IFB, located in Meherpur district, with similar activities. It was inaugurated in October 2007. Since their inception, IMCHC and IJM have conducted 7,481 and 1,846 eye surgeries respectively. 
Two-thirds of people living in the Subcontinent do not utilize health services (8-10) due to geographical isolation $(11,12)$. Mobile hospitals may be able to improve the geographical accessibility to health services. Previous studies in developed countries found that mobile hospitals were an effective method in reaching high-risk individuals who were not in contact with medical services (13-17). In Bangladesh, the IJT mobile hospital has been operational for 12 years and one of the two stationary hospitals under IFB for 9 years and the other one for 4 years. As the socioeconomic development of the country has been improving (18-20), there is an opportunity to see whether the mobile service is still viable.

In 2011, we conducted this study with an objective to compare previous accessibility to eyecare among vision-impaired patients of mobile and stationary hospitals, with cost aspects taken into consideration. The main rationale of mobile services worldwide is to reduce or eliminate inequity in care. In addition to having implications for future planning of IFB, the study may also serve as a model for evaluation of mobile services in developing countries where the pattern of access to eyecare is changing.

\section{MATERIALS AND METHODS}

A cross-sectional study was conducted between May and September 2011. Data on cost and health service statistics of IFB hospitals were obtained from the IFB office, and descriptive statistics were presented.

We assumed that $90 \%$ of the mobile and $80 \%$ of the stationary hospital patients with VI had difficulty in accessing eyecare in the past. To detect this difference of $10 \%$ with an accuracy of $5 \%$ and a power of $80 \%, 219$ subjects were required from each type of hospital. Since two stationary hospitals were included in the study, 110 subjects were recruited from each of those groups.

New patients with chief complaints of difficulty in seeing from one or both eyes and presenting with visual acuity (VA) of less than 6/24 in the worse eye (by Snellen's chart) were eligible for the study. We chose the worse eye as criterion of selection because this level of poor visual acuity would need serious medical attention, although he/she could function with the other better eye. We also used pinhole to correct for refractive error. Patients with impaired cognitive function, hearing problems, and any conditions that would disable or distort their ability to answer questions properly were excluded from the study.

A structured questionnaire was designed to collect data on previous accessibility to other eyecare services, accessibility to IFB hospitals, barriers to access other eyecare services, reasons for accessing IFB hospital services, distance from home to hospital, travel time, appointment time, travelling cost, treatment cost, extra support, and overall satisfaction with the service quality of previously-visited hospitals and IFB hospitals. The subjects were asked to choose the most important barriers to eyecare and reasons for accessing IFB hospitals. The main outcome of this study is accessibility to eyecare.

\section{Ethics}

This study was approved by the Ethics Committee for Research in Human Subjects, Prince of Songkla University, Thailand (EC 54-202-18-5-3). Consent was taken from the authority of IFB and three project areas of IFB prior to conducting the study. Oral and written informed consent was obtained from all participants prior to data collection and eye examination, and the current study adhered to the tenets of the Helsinki Declaration.

\section{Statistical analysis}

Data were entered and validated with Epidata program (version 3.1) (The EpiData Association, Odense, Denmark). R software (version 2.13.1) (R Foundation, Vienna, Australia), and Epicalc package was used for statistical analysis. Median (IQR) and frequencies were used for descriptive statistics. For inferential statistics, the Ranksum test was used for comparison of continuous variables not normally distributed while the chi-square test was used for comparison of categorical variables. The level of statistical significance was set at $\mathrm{p}<0.05$.

\section{RESULTS}

Table 1 displays statistics of services and expenditure of various activities of IFB hospitals. While total patients were not so much different between IJT (mobile) and IMCHC (one of the stationary hospitals), treatment and surgical cost per patient at the former was half of that at the latter. The directions of the difference for other items were similar. Thus, from the IFB perspective, the efficiency of this mobile hospital was comparable to that of a stationary hospital.

Table 2 shows a comparison of demographic characteristics by type of hospital. There were more males than females, and almost all were Muslim. The majority of patients were aged over 60 years and married. The median monthly family income was BDT 5,000-8,000. Thus, more than half of pa- 


\begin{tabular}{|c|c|c|c|c|c|c|c|}
\hline \multirow{2}{*}{$\begin{array}{l}\text { Place of } \\
\text { service }\end{array}$} & \multirow[b]{2}{*}{ Type of service } & \multicolumn{3}{|c|}{2010} & \multicolumn{3}{|c|}{2011} \\
\hline & & $\begin{array}{l}\text { IJT } \\
\text { (n) }\end{array}$ & $\begin{array}{l}\text { IMCHC } \\
\text { (n) }\end{array}$ & $\begin{array}{l}\text { IJM } \\
\text { (n) }\end{array}$ & $\begin{array}{l}\text { IJT } \\
\text { (n) }\end{array}$ & $\begin{array}{l}\text { IMCHC } \\
\text { (n) }\end{array}$ & $\begin{array}{l}\mathrm{IJM} \\
(\mathrm{n})\end{array}$ \\
\hline \multirow[t]{2}{*}{ Outpatients } & Total & 38,867 & 39,999 & 26,453 & 34,978 & 31,521 & 24,041 \\
\hline & Eye service & 22,928 & - & - & 20,379 & - & - \\
\hline \multirow[t]{2}{*}{ In-patients } & Total & 2,161 & 1,825 & 1,026 & 2,427 & 1,300 & 886 \\
\hline & Eye surgery & 1,778 & 1,383 & 766 & 2,047 & 1,039 & 670 \\
\hline \multirow[t]{4}{*}{$\begin{array}{l}\text { Outreach } \\
\text { activities }\end{array}$} & $\begin{array}{l}\text { Training provided } \\
\text { to birth attendants }\end{array}$ & 90 & 348 & 71 & 73 & 300 & 77 \\
\hline & $\begin{array}{l}\text { Attendees to mother } \\
\text { club meeting }\end{array}$ & - & 10,655 & 3,462 & - & 8,942 & 2,661 \\
\hline & Health education & 41,667 & 29,160 & 52,726 & 37,102 & 24,837 & 45,762 \\
\hline & Home-gardening & - & 1,462 & 206 & - & 1,067 & 181 \\
\hline
\end{tabular}

\begin{tabular}{|lccc|}
\hline \multicolumn{4}{|l|}{ Table 1b. Statement of expenditure of hospitals in 2011} \\
\hline \multirow{2}{*}{ Type of expenditure } & IJT & IMCHC & IJM \\
& BDT (\%) & BDT (\%) & BDT (\%) \\
\hline Treatment and surgery & $8,926,012(50)$ & $13,337,306(45)$ & $6,919,618(49)$ \\
Hospital maintenance & $1,199,860(6.8)$ & $1,481,923(5)$ & $861,422(6.1)$ \\
Field programme & $3,748,925(21)$ & $6,816,845(23)$ & $2,965,551(21)$ \\
Staff salaries & $3,052,696(17)$ & $5,365,827(18)$ & $2,541,900(18)$ \\
Administration & $357,040(2)$ & $1,012,586(3.5)$ & $282,433(2)$ \\
Vehicle fuel & $267,781(1.5)$ & $949,928(3.2)$ & $303,616(2.2)$ \\
Vehicle maintenance & $128,942(0.7)$ & $377,658(1.3)$ & $174,532(1.2)$ \\
Staff development & $170,768(1)$ & $296,385(1)$ & $72,597(0.5)$ \\
Total expenditure & $17,852,024(100)$ & $29,638,458(100)$ & $14,121,669(100)$ \\
Treatment and surgical cost per patient & 238 & 406 & 277 \\
\hline IJT=Impact 'Jibon Tari' Floating Hospital; IMCHC=Impact Masudul Haque Memorial Community Health \\
Centre; IJM=Impact 'Jibon Mela'
\end{tabular}

tients in all three hospitals lived below the povertyline, defined by World Bank as income less than US\$ 1.25 per person per day. Overall, the stationary hospitals were more likely to serve the poorer socioeconomic group.

Table 3 shows a comparison of the effect of VI on patient's life, clinical history of chronic disease, and severity of VI. Median time since the first feeling of vision-impairment, the first feeling that visionimpairment hampered daily activities, and the first thoughts of consulting a doctor were not significantly different between types of hospital. Most parameters on VI were similar, though visual acuity of the mobile hospital patients who had never sought eyecare in the past was slightly worse. Patients at the stationary hospitals were more likely to be diabetic and have a history of eye surgery.

Table 4 displays accessibility to other eyecare centres in the past and IFB hospitals in the current visit;
$27.7 \%$ of patients at mobile and $36.8 \%$ at stationary hospitals had visited other eyecare centres in the past. There was little evidence that either group had more problem of access to eyecare in the past, although patients visiting mobile hospital lived, on average, at further distance from the eyecare centre. A significant difference was observed in relation to accessibility to the current hospital. Patients at the mobile hospital lived closer to the hospital but spent more time in travelling, bore less direct cost, needed less extra support, and had a higher level of satisfaction from the service.

Table 5 shows the barriers and reasons for accessing eyecare services. The percentage of patients identifying a barrier to eyecare access in the past was less in the stationary hospitals. Overall, cost was the main barrier to accessing other eyecare centres, which motivated the patients to seek cheaper services at both types of IFB hospitals. Distance was 


\begin{tabular}{|c|c|c|c|}
\hline \multirow{2}{*}{ Demographic characteristics } & \multicolumn{2}{|c|}{ Type of hospital } & \multirow{2}{*}{$\mathrm{p}$ value } \\
\hline & Mobile & Stationary & \\
\hline Age in years* & $60(49.5,65)$ & $60(48,65)$ & 0.637 \\
\hline Sex & & & 0.207 \\
\hline Male & $138(62.7)$ & $124(56.4)$ & \\
\hline Female & $82(37.3)$ & $96(43.6)$ & \\
\hline Religion & & & 1 \\
\hline Muslim & $212(96.4)$ & $213(96.8)$ & \\
\hline Others & $8(3.6)$ & $7(3.2)$ & \\
\hline Marital status & & & 0.033 \\
\hline Single & $1(0.5)$ & $9(4.1)$ & \\
\hline Married & $183(83.2)$ & $180(81.8)$ & \\
\hline Widowed & $36(16.4)$ & $31(14.1)$ & \\
\hline Education level & & & 0.311 \\
\hline No formal education & $127(57.7)$ & $141(64.1)$ & \\
\hline Primary school & 39 (17.7) & $30(13.6)$ & \\
\hline Secondary/Vocational school & $43(19.5)$ & $34(15.5)$ & \\
\hline College and higher & $11(5)$ & $15(6.8)$ & \\
\hline Occupation & & & $<0.001$ \\
\hline Unemployed & $50(22.7)$ & $96(43.6)$ & \\
\hline Farming & $83(37.7)$ & $36(16.4)$ & \\
\hline Others & $41(18.6)$ & $40(18.2)$ & \\
\hline Housewifery & $46(20.9)$ & $48(21.8)$ & \\
\hline Family members* & $5(4,7)$ & $4(2,5.2)$ & $<0.001$ \\
\hline Family income* (BDT) & $8000(4000,15000)$ & $5000(3000,10000)$ & $<0.001$ \\
\hline
\end{tabular}

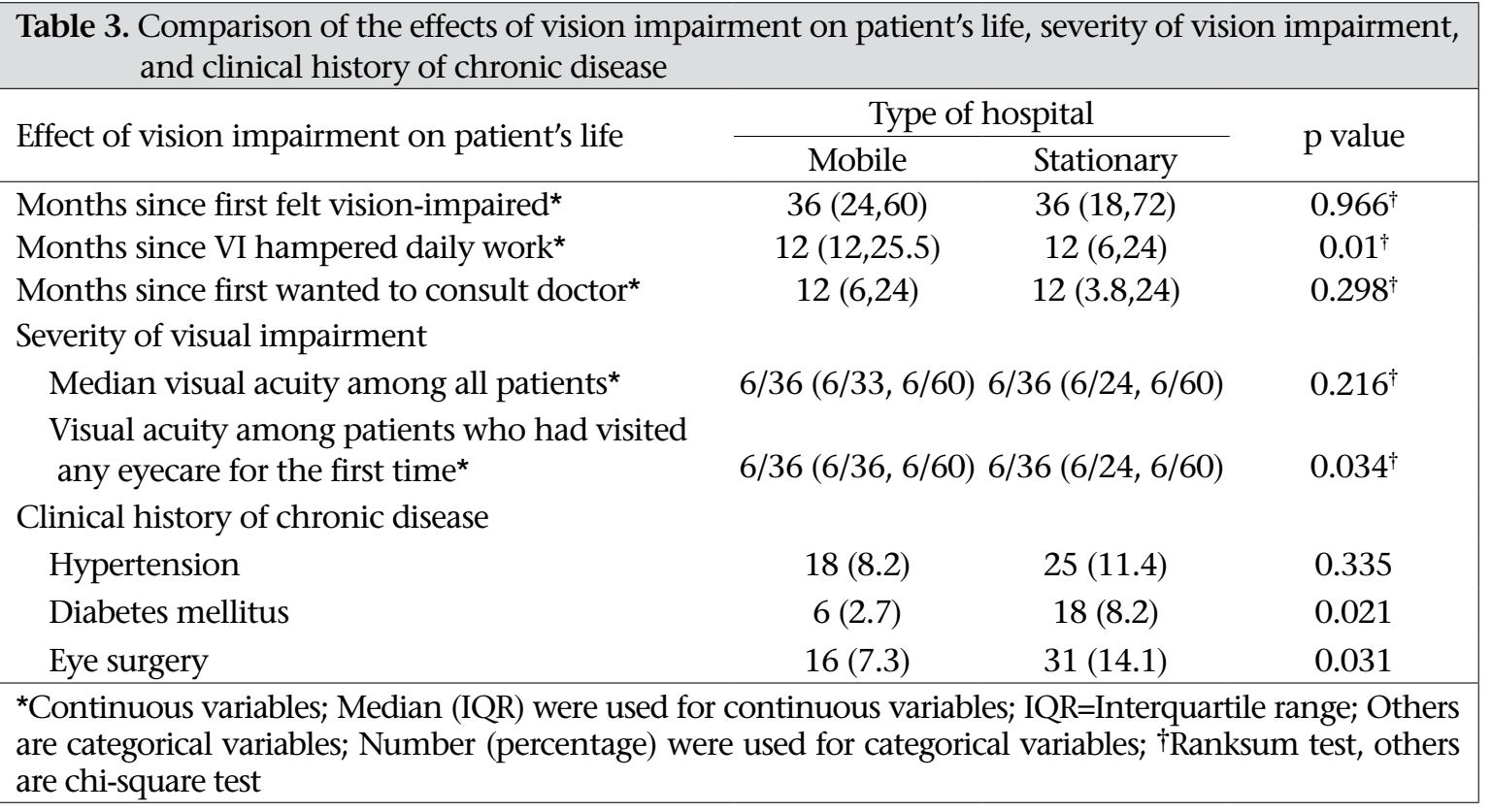




\begin{tabular}{|c|c|c|c|}
\hline \multirow[b]{2}{*}{ Accessibility to other eyecare centres } & \multicolumn{2}{|c|}{ Type of hospital } & \multirow[b]{2}{*}{$\mathrm{p}$ value } \\
\hline & $\begin{array}{c}\text { Mobile } \\
(\mathrm{n}=61)\end{array}$ & $\begin{array}{c}\text { Stationary } \\
(\mathrm{n}=81)\end{array}$ & \\
\hline Ever visited eyecare centre & $61(27.7)$ & $81(36.8)$ & 0.053 \\
\hline Distance to the last-visited eyecare centre* $(\mathrm{km})$ & $22(10,52)$ & $17(5,40)$ & $0.211^{\dagger}$ \\
\hline Travel time* (hr) & $1.5(0.8,3)$ & $1(0.5,2)$ & $0.019^{\dagger}$ \\
\hline Waiting time* $(\mathrm{hr})$ & $0.8(0.2,1.5)$ & $0.7(0.3,1.2)$ & $0.909^{\dagger}$ \\
\hline Indirect cost* (BDT) & $50(20,120)$ & $40(10,100)$ & $0.083^{\dagger}$ \\
\hline Direct cost* (BDT) & $70(30,300)$ & $200(50,300)$ & $0.089^{\dagger}$ \\
\hline Extra support & $33(54.1)$ & $54(66.7)$ & 0.178 \\
\hline Satisfaction with service & $35(57.4)$ & $38(46.9)$ & 0.287 \\
\hline Accessibility to IFB hospitals & $\begin{array}{l}\text { Mobile } \\
(\mathrm{n}=220)\end{array}$ & $\begin{array}{c}\text { Stationary } \\
(n=220)\end{array}$ & \\
\hline Distance to the nearest eyecare centre* $(\mathrm{km})$ & $17.5(11,25)$ & $13.5(5,19)$ & $<0.001^{\dagger}$ \\
\hline Distance to IFB hospital* (km) & $11(5,18.5)$ & $14(6,20)$ & $0.047^{\dagger}$ \\
\hline Travelling time* (hr) & $1(0.7,2)$ & $1(0.5,1.2)$ & $<0.001^{\dagger}$ \\
\hline Waiting time* (hr) & $1.6(0.8,2.5)$ & $1.2(0.6,2.5)$ & $0.073^{\dagger}$ \\
\hline Indirect cost* $(\mathrm{BDT})$ & $25(10,50)$ & $30(10,51.2)$ & $0.349^{\dagger}$ \\
\hline Direct cost* $(\mathrm{BDT})$ & $20(20,20)$ & $20(20,20)$ & $<0.001^{\dagger}$ \\
\hline Need extra support & $123(55.9)$ & $156(70.9)$ & 0.002 \\
\hline Satisfied with service $e^{\dagger \dagger}$ & $191(86.8)$ & $165(75)$ & 0.002 \\
\hline \multicolumn{4}{|c|}{$\begin{array}{l}\text { *Continuous variables; Median (IQR) were used for continuous variables; IQR=Interquartile range; Others } \\
\text { are categorical variables; Number (percentage) were used for categorical variables; †Ranksum test; others are } \\
\text { chi-square test; ‘Satisfied with service" refers to "I was satisfied with the service I received, after I had my treat- } \\
\text { ment"; }{ }^{\dagger \dagger} \text { "Satisfied with service" refers to "Before I had my service, I came to the IFB hospital because I thought } \\
\text { I would be satisfied with the treatment" }\end{array}$} \\
\hline
\end{tabular}

Table 5. Barriers to and reasons for accessing eyecare services

\begin{tabular}{|lcc|}
\hline & \multicolumn{2}{c|}{ Type of hospital } \\
\cline { 2 - 3 } Barrier to other eyecare services & Mobile & Stationary \\
& $\mathrm{N}(\%)$ & $\mathrm{N}(\%)$ \\
\hline Unable to pay direct costs & $124(56.4)$ & $96(43.6)$ \\
Unable to pay indirect costs & $102(46.4)$ & $20(9.1)$ \\
Quality of service not good enough & $47(21.4)$ & $96(43.6)$ \\
Distance too long & $28(12.7)$ & $11(5)$ \\
Unable to come alone & $24(10.9)$ & $5(2.3)$ \\
Travelling time too long & $20(9.1)$ & $5(2.3)$ \\
Waiting time for appointment too long & $12(5.5)$ & $2(0.9)$ \\
Waiting time for consultation too long & $9(4.1)$ & $4(1.8)$ \\
Reasons for accessing IFB hospital service & & \\
$\quad$ Able to pay direct cost & $148(67.3)$ & $103(46.8)$ \\
Satisfied with quality of service§ & $147(66.8)$ & $181(82.3)$ \\
Able to pay indirect cost & $121(55.0)$ & $13(5.9)$ \\
IFB hospital is nearer & $116(52.7)$ & $12(5.5)$ \\
Travelling time is short & $91(41.4)$ & $4(1.8)$ \\
Able to come alone & $13(5.9)$ & $0(0)$ \\
Short waiting time for appointment & $9(4.1)$ & $1(0.5)$ \\
Short waiting time for consultation & $8(3.6)$ & $1(0.5)$ \\
\hline \&"Satisfied with service" refers to "Before I had my service, I came to the IFB hospital because I thought \\
I would be satisfied with the treatment"
\end{tabular}


not the main barrier to accessing other eyecare centres, although more than $52.7 \%$ said it was the main reason for coming to the mobile hospital.

\section{DISCUSSION}

The results suggest that the mobile and stationary hospitals had comparable efficiency in terms of the number of performed surgeries vs costs. All three hospitals serve mainly the poor rural residents predominated by males whose activities were hampered by VI and had been waiting for about one year for consultation. Around one-third ever sought eyecare services elsewhere. Their main barrier to accessing eyecare was more financial than geographical.

Our data showed that the proportion of the patients who had previously accessed eyecare was not statistically significant. This may suggest that mobile service does not always serve the rural population. From the social perspective, mobile services could be efficient if they could visit pockets of untreated cases (21) in areas where healthcare facilities are unavailable. Currently, the mobile hospital has more difficulties in accessing the interior areas of the country, which is gradually becoming inaccessible due to shrinkage of river-ways and loss of waterbodies $(22,23)$. Land transportation is becoming easier due to improvement of roads and highways. For patients in areas accessible by road, the emphasis should be on quality of care (24) rather than geographical accessibility.

The gender issue plays a key role in access to healthcare in developing countries, like Bangladesh
$(25,26)$. The Bangladesh national blindness and low vision survey in 2000 revealed that the prevalence of cataract, the main cause of vision impairment, is slightly higher among females (3). Our study shows that the service recipients are mostly males, which indicates that there is still a huge unmet need for treatment of vision impairment in the rural female population (27). The main reasons for gender disparity appear to be the existing patriarchal, patrilineal, and patrilocal social customs in Bangladesh.

Despite the difficulties in access to public facilities, such as electricity and water supply, the total running cost of IJT (mobile hospital) is still wellcontained. Voluntarism spirit among permanent and visiting staff of mobile hospital allows costs to be lower than the market price. Effective public relation and patient recruitment as well as low level of charge for specialized services enable the mobile hospital to provide a relatively large volume of service per unit time compared to a multi-faceted stationary hospital (28).

The stationary service, on the other hand, is more effective and locally sustainable, especially for health promotion and prevention and people's empowerment. A high activity of such care in stationary hospitals demands higher running costs on human resources and materials and may provide less immediately-perceivable health improvement compared to curative surgery. These, however, may be more effective and efficient from the long-term societal perspective since the majority of diseases and disabilities in the rural area of the community are preventable.

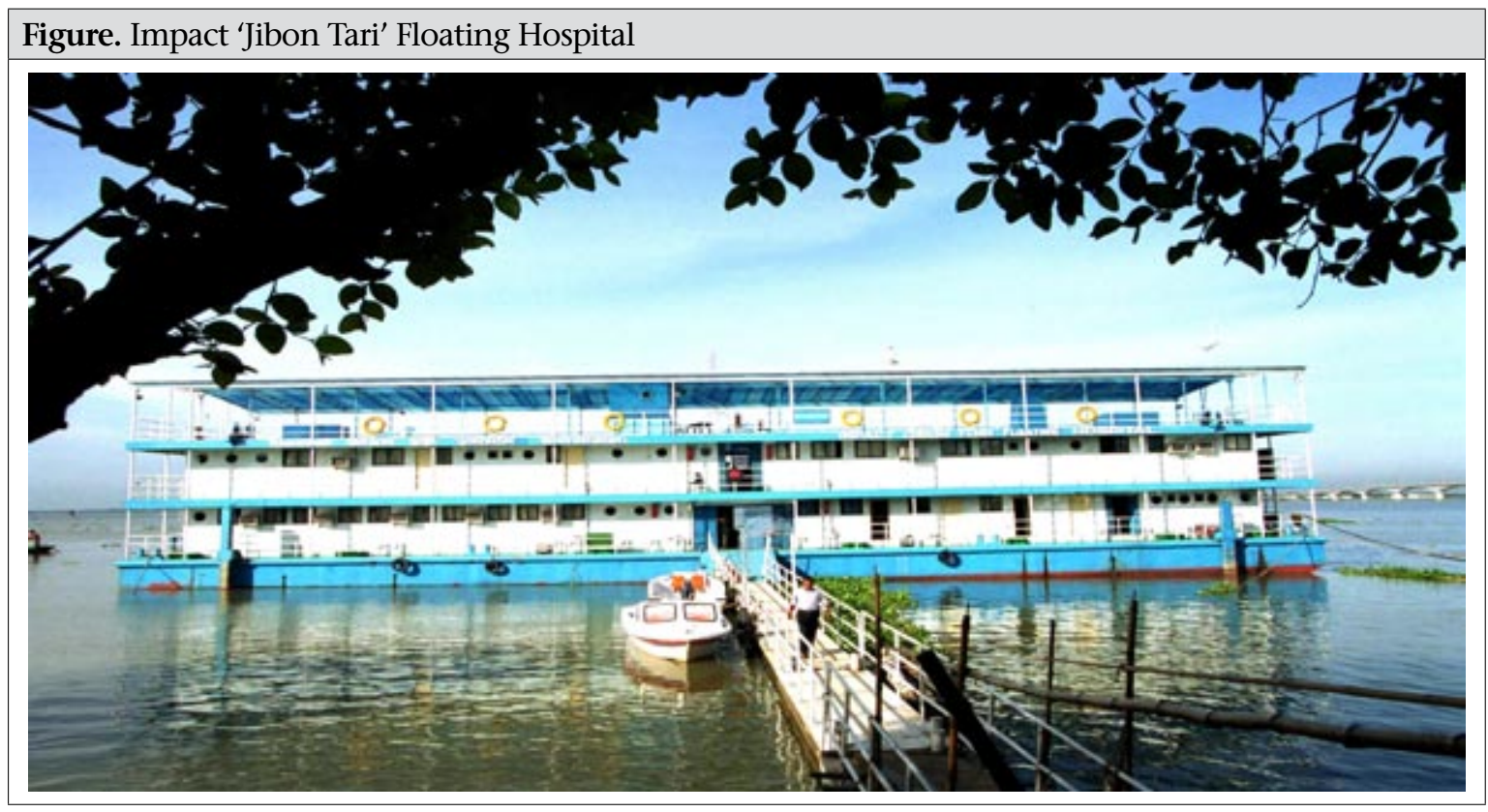


The transition of mobile surgical curative care to stationary integrated care needs to be considered carefully. Our data show that geographic barriers are now a less important problem than financial barriers and perceived quality for eyecare (29-31). If data could be generalized, it would be more important currently to improve the healthcare financial system and quality of care than to aim at the geographic coverage for curative surgery. The mobile hospital, having a higher percentage of patients with accessibility problems, should continue to help remote populations in overcoming these problems.

This study has certain limitations for the fact that IFB hospitals have been there for years. Patients might select to use them due to other reasons as specified in this study. The two types being at different geographic locations would have served different populations; so, comparison must be interpreted with caution.

\section{ACKNOWLEDGEMENTS}

This study is part of the research by the first author to fulfil the requirements for the MSc. degree in Epidemiology from the Prince of Songkla University, Thailand. The authors thank Dr. Joydhan Tanchangya, Senior Medical Officer, Impact 'Jibon Tari' Floating Hospital and Dr. Shaheen, Consultant, Impact Foundation Bangladesh, for advice on proposal development and diagnosis of disease. Epidemiology unit of the Prince of Songkla University is supported by the National Science and Technology Development Agency of Thailand through Research Chair Grant given to Professor Virasakdi Chongsuvivatwong (second author of this article).

\section{REFERENCES}

1. World Health Organization. Visual impairment and blindness. Geneva: World Health Organization, 2012. (http://www.who.int/mediacentre/ factsheets/ fs282/en/, accessed on 15 February 2011).

2. Dandona L, Dandona R. What is the global burden of visual impairment? BMC Med 2006;4:6.

3. Dineen BP, Bourne RRA, Ali SM, Huq DMN, Johnson GJ. Prevalence and causes of blindness and visual impairment in Bangladeshi adults: results of the National Blindness and Low Vision Survey of Bangladesh. Br J Ophthalmol 2003;87:820-8.

4. Bangladesh. Ministry of Planning. Monthly statistical bulletin—Bangladesh: February—2011. Dhaka: Bangladesh Bureau of Statistics, Statistics and Informatics Division, Ministry of Planning, People's Republic of Bangladesh, 2011. 204 p.
5. World Bank. World development indicators 2004. Washington, DC: World Bank, 2004. 386 p.

6. Bangladesh. Ministry of Health and Family Welfare. Health Bulletin 2011. Dhaka: Directorate General of Health Services, Ministry of Health and Family Welfare, Government of the People's Republic of Bangladesh, 2011. $251 \mathrm{p}$.

7. Bangladesh. Ministry of Health and Family Welfare. National Eye Care (NEC): operational plan. Dhaka: Health Population and Nutrition Sector Development Program, Directorate General of Health Services, Ministry of Health and Family Welfare, Government of the People's Republic of Bangladesh, 2011. $55 \mathrm{p}$.

8. Cockcroft A, Milne D, Andersson N. Bangladesh Health and population sector programme 1998-2003: the third service delivery survey; final report. Ottawa: CIETcanada, 2004. 85 p.

9. The World Bank Office, Dhaka. Comparative advantages of public and private health care providers in Bangladesh. Washington, DC: The World Bank, 2005:1-75. (Bangladesh development series paper no. 4).

10. Nirmalan PK, Katz J, Robin AL, Krishnadas R, Ramakrishnan R, Thulasiraj RD et al. Utilisation of eye care services in rural south India: the Aravind Comprehensive Eye Survey. BrJOphthalmol 2004;88:123741.

11. Chan L, Hart LG, Goodman DC. Geographic access to health care for rural Medicare beneficiaries. J Rural Health 2006;22:140-6.

12. Nemet GF, Bailey AJ. Distance and health care utilization among the rural elderly. Soc Sci Med 2000;50:1197208.

13. Dube C, Nozaki I, Hayakawa T, Kakimoto K, Yamada N, Simpungwe JB. Expansion of antiretroviral treatment to rural health centre level by a mobile service in Mumbwa district, Zambia. Bull World Health Organ 2010;88:788-91.

14. Edgerley LP, El-Sayed YY, Druzin ML, Kiernan M, Daniels KI. Use of a community mobile health van to increase early access to prenatal care. Matern Child Health J 2007;11:235-9.

15. Mauad EC, Silva TB, Latorre MR, Vieira RAC, Haikel RL, Jr., Vazquez VL et al. Opportunistic screening for skin cancer using a mobile unit in Brazil. BMC Dermatol 2011;11:12.

16. Kahn RH, Moseley KE, Thilges JN, Johnson G, Farley TA. Community-based screening and treatment for STDs: results from a mobile clinic initiative. Sex Transm Dis 2003;30:654-8.

17. McGhee SM, Ho LM, Cheung AWL, Abdullah ASM, 
Chan CWH, Yeung ACP. Evaluation of a mobile clinic for older people in Shamshuipo. Hong Kong Med J 2007;13(Suppl 1):S13-5.

18. Ahluwalia IJ, Hussain Z. Development Achievements and Challenges. Econ Polit Weekly 2004;39:4013-22.

19. Ahluwalia IJ, Mahmud W. Economic Transformation and Social Development in Bangladesh. Econ Polit Weekly 2004;39:4009-11.

20. Mahmud W. Social Development in Bangladesh: pathways,surprises and challenges. Indian J Hum Dev 2008;2:79-92.

21. Ellen JM, Bonu S, Arruda JS, Ward MA, Vogel R. Comparison of clients of a mobile health van and a traditional STD clinic. J Acquir Immune Defic Syndr 2003;32:388-93.

22. Ahmed AU. Adaptation options for managing waterrelated extreme events under climate change regime: Bangladesh perspectives. In: Mirza MMQ, Ahmad $\mathrm{QK}$, editors. Climate change and water resources in South Asia. London: Taylor \& Francis, 2005:255-78.

23. Bangladesh. Ministry of Environment and Forests. Climate change, gender and vulnerable groups in Bangladesh: climate change adaptation research. Dhaka: Climate Change Cell, Department of Environment, Ministry of Environment and Forests, People's republic of Bangladesh, 2008. 82 p.

24. Siddiqui N, Khandaker SA. Comparison of services of public, private and foreign hospitals from the per- spective of Bangladeshi patients. J Health Popul Nutr 2007;25:221-30.

25. Choudhury KK, Hanifi MA, Rasheed S, Bhuiya A. Gender inequality and severe malnutrition among children in a remote rural area of Bangladesh. J Health Popul Nutr 2000;18:123-30.

26. Okojie CE. Gender inequalities of health in the Third World. Soc Sci Med 1994;39:1237-47.

27. Ahmed SM, Adams AM, Chowdhury M, Bhuiya A. Gender, socioeconomic development and healthseeking behaviour in Bangladesh. Soc Sci Med 2000; 51:361-71.

28. Dyer JJ. Comparative costs of mobile and fixed-clinic primary health care services. S Afr Med J 1996;86:52830.

29. Jadoon Z, Shah SP, Bourne R, Dineen B, Khan MA, Gilbert CE et al. Cataract prevalence, cataract surgical coverage and barriers to uptake of cataract surgical services in Pakistan: the Pakistan National Blindness and Visual Impairment Survey. Br J Ophthalmol 2007;91:1269-73.

30. Fletcher AE, Donoghue M, Devavaram J, Thulasiraj $\mathrm{RD}$, Scott S, Abdalla $\mathrm{M}$ et al. Low uptake of eye services in rural India: a challenge for programs of blindness prevention. Arch Ophthalmol 1999;117:1393-9.

31. Sen B, Acharya S. Health and poverty in Bangladesh. World Health 1997;50:28-9. 